\title{
Perineal massage in labour and prevention of perineal trauma: randomised controlled trial
}

\author{
Georgina Stamp, Gillian Kruzins, Caroline Crowther
}

\begin{abstract}
Objective To determine the effects of perineal massage in the second stage of labour on perineal outcomes. Design Randomised controlled trial.

Participants At 36 weeks' gestation, women expecting normal birth of a singleton were asked to join the study. Women became eligible to be randomised in labour if they progressed to full dilatation of the cervix or $8 \mathrm{~cm}$ or more if nulliparous or $5 \mathrm{~cm}$ or more if multiparous. 1340 were randomised into the trial. Intervention Massage and stretching of the perineum during the second stage of labour with a water soluble lubricant.
\end{abstract}

Main outcome measures Primary outcomes: rates of intact perineum, episiotomies, and first, second, third, and fourth degree tears. Secondary outcomes: pain at three and 10 days postpartum and pain, dyspareunia, resumption of sexual intercourse, and urinary and faecal incontinence and urgency three months postpartum.

Results Rates of intact perineums, first and second degree tears, and episiotomies were similar in the massage and the control groups. There were fewer third degree tears in the massage group $(12(1.7 \%) v$ 23 (3.6\%); absolute risk 2.11, relative risk 0.45 ; $95 \%$ confidence interval 0.23 to $0.93, \mathrm{P}<0.04$ ), though the trial was underpowered to measure this rarer outcome. Groups did not differ in any of the secondary outcomes at the three assessment points. Conclusions The practice of perineal massage in labour does not increase the likelihood of an intact perineum or reduce the risk of pain, dyspareunia, or urinary and faecal problems.

\section{Introduction}

Perineal trauma during and after childbirth is associated with short and long term morbidity for women. It can results in urinary and faecal incontinence, painful intercourse, and persistent perineal pain. ${ }^{1}$ These problems are less likely in women whose perineum remains intact, ${ }^{2}$ the achievement of which has long been highly regarded. ${ }^{3}{ }^{4}$ Perineal trauma, particularly from routine episiotomy, is painful, often considered unnecessary, and impacts on a woman's sexuality and self esteem. Strong evidence in support of restricting the use of episiotomy is now well established from systematic review of the randomised trials. ${ }^{6}$

The protective value of perineal massage during pregnancy has been evaluated in two randomised trials. In the United Kingdom, a trial of 861 nulliparous women found a non-significant benefit of $6 \%$ in the prevalence of perineal trauma $(75 \% v 69 \%, \mathrm{P}<0.07){ }^{7}$ In a trial from Canada of women having their first vaginal delivery, researchers hypothesised that antenatal perineal massage would result in an increase in the rate of intact perineum of $10 \% .^{8}$ They found a nonsignificant increase of $9 \%$ (from $15 \%$ to $24 \%$ ). At follow up three months postpartum there was no difference in perineal function between women who had or had not received perineal massage. ${ }^{9}$

Stretching and massaging of the perineum during the second stage of labour has been promoted as a means of relaxing the perineum and possibly preventing tearing and the need for episiotomy. ${ }^{10}$ In 1989 and again recently the lack of well conducted randomised trials of perineal massage in the second stage of labour was highlighted. ${ }^{12}{ }^{13}$ We designed and conducted this large randomised trial to address this need.

\section{Methods}

We surveyed midwives working in seven delivery suites and birth centres in four Australian states to ascertain their views and practices in the second stage of labour. ${ }^{14}$ In relation to perineal massage in labour, $81(43 \%)$ of 189 midwives were undecided as to its value, $36(19 \%)$ did not agree with the practice, and 23 (12\%) did not feel competent to perform it. This information helped to identify potential barriers and educational needs of midwives who would participate in the trial, conduct the massage, and document outcomes.

\section{Protocol}

A research midwife invited potentially eligible women to take part in the trial in the antenatal clinics of the three tertiary participating hospitals. English speaking women at their 36 week visit who were expecting a normal vaginal birth of a single baby were eligible. Signed consent to be randomised in labour was obtained and an identifying stamp affixed to the case notes. Women presenting in uncomplicated labour were eligible to be randomised when they progressed to a visible vertex, full dilatation of the cervix, or $8 \mathrm{~cm}$ or more if nulliparous, or $5 \mathrm{~cm}$ or more if multiparous.

\section{Assignment}

Women who met the criteria were randomised by the attending midwife in one of two ways. At the coordinating centre in hospital 1 a telephone call was made to the emergency department. Here, the duty midwife or clerk opened the next sequentially numbered, double packed, sealed envelope, taken from a box marked either nulliparous or multiparous. For hospitals 2 and 3 the attending midwife opened the next trial envelope from an identical arrangement in the delivery suite. The randomisation schedules and envelopes were prepared in batches of 100 by a research assistant not involved in care of the women. Stratification was by nulliparity and multiparity.

Women in the intervention group received massage and stretching of the perineum with each contraction during the second stage of labour. The midwife inserted two fingers inside the vagina and using a sweeping motion, gently stretched the perineum with water soluble lubricating jelly, stopping if it was uncomfortable for the woman. At the three

\section{Centre for Research into Nursing and Health Care, \\ University of South \\ Australia and North \\ Western Adelaide \\ Health Service, \\ North Terrace, \\ Adelaide, SA 5000, \\ Australia \\ Georgina Stamp \\ senior research fellow \\ Women's and \\ Children's Hospital, \\ North Adelaide, \\ SA 5006 \\ Gillian Kruzins \\ research midwife \\ Department of \\ Obstetrics and \\ Gynaecology, \\ University of \\ Adelaide, Women's \\ and Children's \\ Hospital, North \\ Adelaide \\ Caroline Crowther \\ associate professor \\ Correspondence to: \\ G Stamp \\ georgie.stamp@ \\ unisa.edu.au}

BMJ 2001;322:1277-80 
hospitals midwives were instructed in perineal massage by regular staff development sessions with verbal instruction, a specially made video, and an illustrated pamphlet using a series of detailed drawings and written instructions. For women in the control group the midwife was instructed to use her or his usual technique but to refrain from using perineal massage.

Masking

Because of the nature of the intervention it was not possible to mask the treatment allocation. Educational strategies informed midwives of the aim that as many women as possible should receive the treatment to which they had been randomised. When practicable the attending midwife was asked to obtain an independent perineal assessment from a caregiver not involved in the birth.

Primary hypothesis and secondary outcomes We designed a 1:1 two group randomised trial to test the primary hypothesis that women who receive perineal massage in the second stage of labour will have a 23\% increase in the likelihood of an intact perineum (from $32.5 \%$ to $40 \%$ ) compared with the group who did not receive perineal massage (control). This required a sample size of 1340 women $(\mathrm{P}<0.05,80 \%$ power). The rate of intact perineums varied from $30 \%$ to $33 \%$ in the study hospitals (Queen Victoria Hospital, clinical information services data for 1994). Discussions with midwives in these hospitals in the planning stages indicated they would consider changes to their practice for the improvement hypothesised but not less. Standard definitions of perineal trauma were used: intact perineum (not requiring suturing); first degree tear (involves skin of the perineum and vaginal mucosa); second degree tear (involves deeper layers of perineal muscle); third degree tear (involves the anus); fourth degree tear (involves the anus and rectal mucosa). ${ }^{15}$

Secondary outcomes were pain at three days, 10 days, and three months postpartum, and resumption of sexual intercourse, dyspareunia, and urinary and faecal urgency and incontinence at three months. We also collected subsidiary labour and infant outcomes.

\section{Follow up and analysis}

The research midwife collected demographic data. Data packs documenting birth outcomes, study group allocation, whether perineal massage was conducted and its duration, and detailed perineal outcomes were completed by the attending midwife and collected and checked daily by the research midwife. Secondary outcomes of pain and urinary and bowel problems were collected from questionnaires and modified from those used in the West Berkshire episiotomy trial. ${ }^{16}$ At day 3 and day 10 pain outcomes were collected by self report questionnaire on the postnatal ward or by a telephone call from the research midwife. Data on pain and on urinary, bowel, and sexual intercourse outcomes were collected at three months postpartum by postal survey. Secondary outcomes were not collected from women who had an emergency caesarean section.

We entered all data on a database using EpiInfo (version 6), a database and statistics system. ${ }^{17}$ Data were analysed with a parametric test (Student's $t$ test) for continuous variables and non-parametric tests $\left(\chi^{2} 2 \times 2\right.$ tables, relative risks, and absolute risks when appropriate) for categorical variables. Comparisons were made between trial groups for the primary and secondary outcomes. For the five primary outcomes (intact perineum, episiotomy, and first, second, and third degree tears) we considered $\mathrm{P}<0.01$ as significant. Primary analyses were based on all women entered into the trial (intention to treat). Secondary analyses included stratification by parity, perineal outcomes by independent assessors, and compliance with the intervention.

The trial was conducted from March 1995 to January 1998 in three hospitals with around 7000 births a year. ${ }^{18}$ Separate ethics approval was obtained from each hospital. An independent data monitoring committee was set up to advise the steering group. The researchers undertook the data analysis on completion of data entry and after the last participant had been followed up for three months.

\section{Results}

Of the 3050 potentially eligible women approached in the antenatal clinic, 2291 (75\%) consented and 759 declined (figure). The main reasons women declined were because they did not want massage (231), were not interested (193), were satisfied by previous massage-free outcome (78), were too anxious when approached (50), wanted no interference (52), wanted to try massage and therefore were not prepared to be randomised (53), and various other reasons (102). From the potentially eligible women who gave consent, 1340 were randomised into the trial. Recruitment stopped when the sample size was reached. The main reasons for women not being randomised were caesarean section (217), instrumental birth (105), no reason

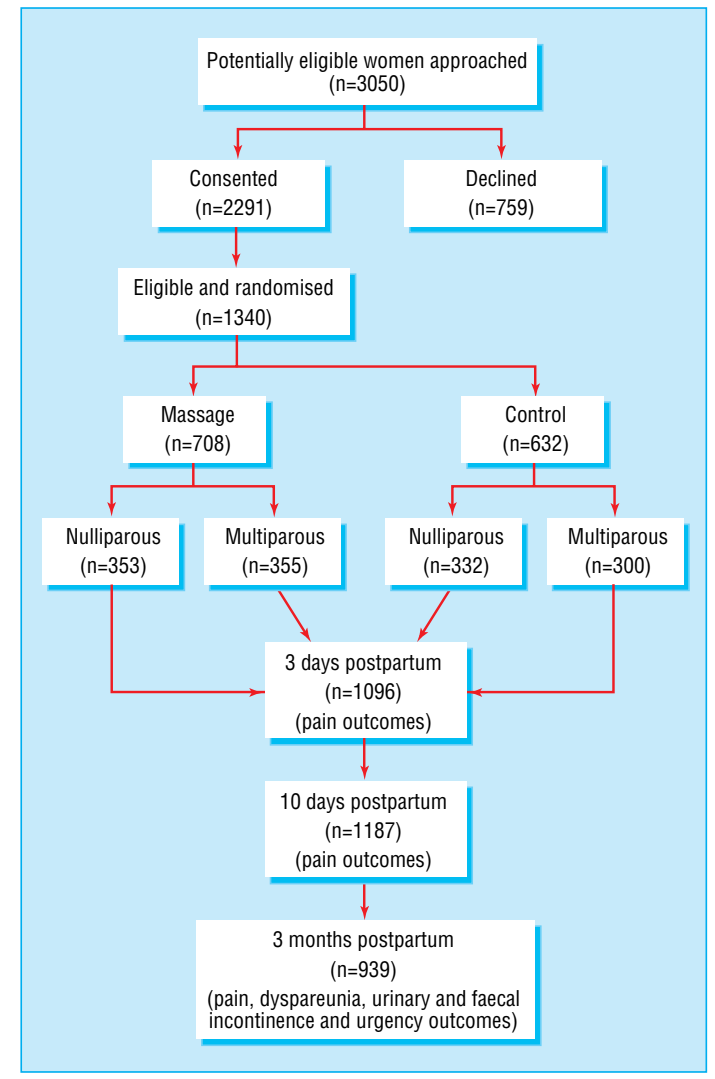

Flow of participants 
given (168), woman changed her mind (112), rapid progress (121), the midwife forgot (77), the midwife was too busy (80), and various other reasons (71). Six months after the trial, midwives were surveyed as to their current views and practices and why women in their care were not randomised or did not receive treatment as allocated. ${ }^{19}$

The groups at trial entry were similar in age, parity, previous perineal trauma, and previous operative vaginal delivery. In addition, the few women who had used antenatal perineal massage during this pregnancy were equally distributed between groups (table 1).

We found no differences in rates of intact perineums between the intervention and control groups (table 2). When we carried out subanalysis by parity the rate for nulliparous women was $18 \%$ (63/353) in the massage group and 20\% (67/332) in the control group (absolute risk 1.13, relative risk 0.88 (95\% confidence interval 0.65 to 1.21$), \mathrm{P}<0.50$ ). For multiparous women the rates were $38 \%(135 / 355)$ and $35 \%(104 / 300)$ (absolute risk 0.91, relative risk 1.10 (0.89 to 1.35$), \mathrm{P}<0.42)$.

Likewise, we found no differences in number of episiotomies or first and second degree tears (table 2). However, there was a trend towards a reduced risk for the rarer outcome of a third degree tear in the perineal massage group (table 2). The only fourth degree tear was sustained by a woman in the control group. Data on perineal assessment by an independent caregiver were available for 1053 (79\%) women. Results from subanalysis of these data were similar in all categories for the primary outcome, including third degree tears (massage 1.6\% (9/564) v 3.3\% (16/489); absolute risk 2.06, relative risk 0.49 ( 0.22 to 1.09$), \mathrm{P}<0.07)$.

We found no differences between the treatment groups in the secondary outcomes of pain at three days, 10 days, and three months or in dyspareunia and resumption of sexual intercourse at three months postpartum (table 3 ). We asked women if they would participate in such a trial again. Of the $892(95 \%)$ respondents who completed this section, 622 said yes, 222 said maybe, and 46 said no. We found no differences between the groups for urinary or bowel urgency or loss of control at follow up, though a considerable number of women in both treatment groups still had reduced urinary control (table 3).

Birth outcomes (including emergency caesarean sections) and infant outcomes were similar between the groups (table 4). Although differences between groups in the length of the second stage was not a hypothesis, the mean length of the second stage for nulliparous women in the massage group was $11 \mathrm{~min}$ utes shorter than in the control group $(\mathrm{P}<0.05)$.

Table 1 Comparability of groups at trial entry. Figures are number of participants unless stated otherwise

\begin{tabular}{lcc} 
Characteristics at entry & $\begin{array}{c}\text { Massage group } \\
(\mathbf{n = 7 0 8 )}\end{array}$ & $\begin{array}{c}\text { Control group } \\
(\mathbf{n}=\mathbf{6 3 2})\end{array}$ \\
\hline Mean age (years): & 25.5 & 26.6 \\
\hline Nulliparous & 29.0 & 29.2 \\
\hline Multiparous & 43 & 39 \\
\hline Antenatal massage during this pregnancy & 355 & 300 \\
\hline Multiparous & 260 & 232 \\
\hline Previous perineal trauma & 104 & 70 \\
\hline Previous instrumental birth & 34 & 39 \\
\hline Previous caesarean section & &
\end{tabular}

\begin{tabular}{lccccc} 
Table 2 Comparison of perineal outcomes between treatment groups & $\begin{array}{c}\text { Massage } \\
\text { group } \\
\mathbf{( n = 7 0 8 )}\end{array}$ & $\begin{array}{c}\text { Control } \\
\text { group } \\
(\mathbf{n}=\mathbf{6 3 2})\end{array}$ & $\begin{array}{c}\text { Absolute } \\
\text { risk }\end{array}$ & $\begin{array}{c}\text { Relative risk } \\
\mathbf{( 9 5 \%} \mathbf{~ C l )}\end{array}$ & P value \\
\hline Outcome & 198 & 171 & 0.97 & $1.03(0.87$ to 1.23$)$ & 0.76 \\
\hline Intact perineum & 176 & 170 & 1.08 & $0.92(0.77$ to 1.11$)$ & 0.43 \\
\hline Episiotomy & 122 & 106 & 0.97 & $1.03(0.81$ to 1.30$)$ & 0.88 \\
\hline First degree tear & 190 & 164 & 0.97 & $1.03(0.86$ to 1.24$)$ & 0.76 \\
\hline Second degree tear & 12 & 23 & 2.11 & $0.47(0.23$ to 0.93$)$ & 0.04 \\
\hline Third degree tear & 12 & 1 & & Unspecified & \\
\hline Fourth degree tear & 0 & &
\end{tabular}

Table 3 Comparison of pain outcome at 3 days, 10 days, and 3 months postpartum and sexual, bowel, and bladder outcomes at 3 months postpartum between treatment groups

\begin{tabular}{|c|c|c|c|c|c|}
\hline & $\begin{array}{l}\text { Massage } \\
\text { group }\end{array}$ & $\begin{array}{l}\text { Control } \\
\text { group }\end{array}$ & $\begin{array}{l}\text { Absolute } \\
\text { risk }\end{array}$ & $\begin{array}{l}\text { Relative risk } \\
(95 \% \mathrm{Cl})\end{array}$ & $P$ value \\
\hline \multicolumn{6}{|l|}{3 days } \\
\hline No of women & 597 & 499 & & & \\
\hline Vaginal pain & 416 & 359 & 1.03 & 0.97 (0.90 to 1.05$)$ & 0.45 \\
\hline $\begin{array}{l}\text { Worst pain moderate or } \\
\text { severe }\end{array}$ & 210 & 192 & 1.09 & 0.91 (0.78 to 1.07$)$ & 0.28 \\
\hline \multicolumn{6}{|l|}{10 days } \\
\hline No of women & 632 & 555 & & & \\
\hline Vaginal pain & 184 & 187 & 1.16 & 0.86 (0.73 to 1.02$)$ & 0.10 \\
\hline $\begin{array}{l}\text { Worst pain moderate or } \\
\text { severe }\end{array}$ & 56 & 63 & 1.27 & $0.78(0.55$ to 1.10$)$ & 0.18 \\
\hline \multicolumn{6}{|l|}{3 months } \\
\hline No of women & 503 & 436 & & & \\
\hline Vaginal pain & 58 & 54 & 1.07 & 0.93 (0.66 to 1.32$)$ & 0.76 \\
\hline Dyspareunia & 78 & 68 & 1.01 & 0.99 (0.74 to 1.34$)$ & 0.96 \\
\hline Intercourse not resumed & 49 & 60 & 1.41 & 0.71 (0.50 to 1.01$)$ & 0.07 \\
\hline $\begin{array}{l}\text { Worst pain moderate or } \\
\text { severe }\end{array}$ & 19 & 14 & 0.85 & 1.18 (0.60 to 2.32$)$ & 0.77 \\
\hline Urinary urgency & 139 & 111 & 0.92 & 1.09 (0.88 to 1.34$)$ & 0.50 \\
\hline Loss of urinary control & 123 & 115 & 1.08 & 0.93 (0.74 to 1.15$)$ & 0.55 \\
\hline Bowel urgency & 115 & 111 & 1.11 & 0.90 (0.72 to 1.13$)$ & 0.39 \\
\hline Loss of bowel control & 36 & 35 & 1.12 & 0.89 (0.57 to 1.39$)$ & 0.70 \\
\hline
\end{tabular}

Table 4 Additional labour and birth outcomes. Figures are numbers of participants unless stated otherwise

\begin{tabular}{|c|c|c|c|c|}
\hline Birth outcomes & $\begin{array}{c}\text { Massage } \\
\text { group } \\
(\mathrm{n}=708)\end{array}$ & $\begin{array}{c}\text { Control } \\
\text { group } \\
(\mathrm{n}=632)\end{array}$ & $\begin{array}{c}\text { Relative risk } \\
(95 \% \mathrm{Cl})\end{array}$ & $P$ value \\
\hline Normal vaginal birth & 569 & 501 & $1.01(0.96$ to 1.07$)$ & 0.66 \\
\hline Emergency caesarean & 24 & 23 & 0.93 (0.53 to 1.63$)$ & 0.92 \\
\hline Postpartum haemorrhage (>500 ml) & 45 & 44 & $0.91(0.61$ to 1.36$)$ & 0.73 \\
\hline \multicolumn{5}{|l|}{ Mean length second stage (mins): } \\
\hline Nulliparous & 84.0 & 94.6 & & 0.05 \\
\hline Multiparous & 37.6 & 39.2 & & 0.69 \\
\hline \multicolumn{5}{|l|}{ Mean birth weight $(g)$ : } \\
\hline Nulliparous & 3427 & 3437 & & 0.76 \\
\hline Multiparous & 3596 & 3591 & & 0.96 \\
\hline Apgar score $<7$ at 5 minutes & 9 & 9 & 0.89 (0.36 to 2.23$)$ & 0.10 \\
\hline Use of oxygen at birth & 205 & 157 & $1.17(0.98$ to 1.39$)$ & 0.10 \\
\hline
\end{tabular}

\section{Discussion}

Stretching and massage of the perineum in the second stage of labour, sometimes known as "ironing out the perineum," has been promoted by midwives. ${ }^{20}$ Midwives' opinions are divided as to its value. ${ }^{15}$ To the best of our knowledge this is the first randomised trial that evaluates the procedure during labour. We found no benefit from massage on rates of intact perineums and trauma, pain, or urinary, faecal, and sexual outcomes at any assessment point.

The trial was powered to detect a $23 \%$ difference in the likelihood an intact perineum, a difference considered relevant by practising midwives. However, the trial 


\section{What is already known on this topic}

Perineal trauma during vaginal birth and its sequelae, including urinary and faecal incontinence, dyspareunia, and persistent pain, have a negative impact on the sexuality, self esteem, and quality of life of countless women each year

Perineal massage conducted antenatally has some benefit in reducing the risk of perineal trauma

Perineal massage in the second stage of labour has been promoted and practised without sound evidence of its effectiveness

\section{What this study adds}

Perineal massage in the second stage of labour did not have any effect on the likelihood of an intact perineum, perineal trauma, pain, or subsequent sexual, urinary or faecal outcomes but was not harmful

The results support midwives in following their usual practice while taking account of the preferences of individual women

was underpowered to assess the uncommon outcome of third degree tears, and the suggestion of a possible protective effect from the massage may be a chance finding. As anal injury during vaginal birth constitutes serious morbidity, this warrants further research with a larger sample. To show reliably a decrease in third degree tears from $3.6 \%$ to $1.7 \%$ would have required a sample of 2448.

Although perineal massage in labour did not increase the likelihood of an intact perineum, our trial does provide good evidence of lack of harm that in itself may be of value. In view of these findings, we suggest that midwives follow their usual practice while taking into account the preferences of individual women.

We thank all the women and midwives who participated in this trial. We also thank Jennifer Sleep for use of the perineal outcomes questionnaire. Julie Pratt demonstrated on video the procedure for perineal massage in labour and Richard Sproggs produced the video. Bronny Rouse designed the drawings for the educational package. Research liaison midwives at three sites supported the trial. Bronny Rouse liaised with and supported midwives at the coordinating site for the first two years and Chris Coombs, Patrice O'Loughlin, and Aurianne Webber performed similar roles at the other two sites for the duration of the trial. Sue Lewis was a research midwife for the first two years and Karen Bentley for the final year. Diana Elbourne, Jennifer Sleep, and Sue McDonald commented on the draft protocol.

Contributors: GS initiated the study, formulated the research questions, participated in the protocol design, drafted the grant application, was principal investigator for the trial, conducted data analysis, and drafted the paper. GK coordinated the trial, undertook recruitment, educated participating midwives, participated in data collection and analysis, presented results, and contributed to the writing of the paper. CC participated in the protocol design, contributed to the grant application, was involved in discussion of core ideas from study design to data analysis, and contributed to the writing of the paper. GS is guarantor.

Funding: Research and Development Grants Advisory Committee of the Commonwealth Department of Health Housing and Community Services (now National Health and Medical Research Council) and the Australian College of Midwives.

Competing interest: Johnson and Johnson provided water soluble lubricant for the perineal massage.

1 Johanson R. Perineal massage for prevention of perineal trauma in childbirth. Lancet 2000;355:250-1.

2 Klein MC, Gauthier RJ, Robbins JM, Kaczorowski J, Jorgensen SH, Franco $\mathrm{ED}$, et al. Relationship of episiotomy to perineal trauma and morbidity, sexual dysfunction and pelvic floor relaxation. Am J Obstet Gynecol 1994;71:591-8.

3 Myles MF. A textbook for midwives. Edinburgh: Livingstone, 1953:304-5.

4 Sleep J. Physiology and management of the second stage of labour. In: Bennett VR, Brown LK, eds. Myles textbook for midwives. London: Churchill Livingstone, 1993:199-215.

5 Kitzinger S, Simkin P. Episiotomy and the second stage of labour. Seattle: Pennypress, 1984 .

6 Carolli G, Belizan J. Episiotomy for vaginal birth. Cochrane Database Syst Rev 2001;(1):CD000081.

7 Shipman MK, Boniface DR, Tefft ME, McCloghry F. Antenatal perineal massage and subsequent perineal outcomes: a randomised controlled trial. Br J Obstet Gynaecol 1997;104:787-91.

8 Labrecque M, Eason E, Marcoux S, Lemiex F, Pinault JJ, Feldman P, et al. Randomized controlled trial of prevention of perineal trauma by perineal massage during pregnancy. Am J Obstet Gynecol 1999;180:593-600.

9 Labrecque M, Eason E, Marcoux S. Randomized trial of perineal massage during pregnancy: perineal symptoms three months after delivery. Am J Obstet Gynecol 2000;182:76-80.

10 Gaskin IM. Spiritual midwifery. Summertown, TN: Book Publishing Co, 1978:360.

11 Flint C. Sensitive midwifery. London: Heinemann, 1986:101-2.

12 Sleep J, Roberts J, Chalmers I. Care during the second stage of labour. In: Chalmers I, Enkin M, Keirse MJNC, eds. Effective care in pregnancy and childbirth. Oxford: Oxford University Press, 1989:1129-44.

13 Renfrew MJ, Hannah W, Albers L, Floyd E. Practices that minimize trauma to the genital tract in childbirth: a systematic review of the literature Birth 1998:25:143-60.

14 Stamp GE. Care of the perineum in the second stage of labour: a study of views and practices of Australian midwives. Midwifery 1997;13:100-4.

15 Ball JA. Complications of the puerperium: In: Bennett VR, Brown LK, eds. Myles textbook for midwizes. London: Churchill Livingstone, 1993:478.

16 Sleep J, Grant A, Garcia J, Elbourne D, Spencer J, Chalmers I. West Berkshire perineal management trial. BMJ 1984;289:587-90.

17 Dean AG, Dean JA, Burton AH, Dicker RC. Epilnfo version 6: a word processing, database and statistics program for epidemiology on microcomputers. Stone Mountain, GA: UDS Incorporated, 1994.

18 Chan A, Scott J, Keane R. Pregnancy outcome in South Australia in 1997. Adelaide: South Australian Health Commission, 1998.

19 Stamp GE, Kruzins G. A survey of midwives who participated in a randomised trial of perineal massage in labour. Aust J Mid (in press).

20 Enkin M, Keirse MJNC, Neilson J, Crowther C, Duley L, Hodnett E, et al, eds. A guide to effective care in pregnancy and childbirth. Oxford: Oxford University Press, 2000

(Accepted 8 March 2001)

\section{One hundred years ago The medical regulation of marriage}

Indiana has now joined in the endeavour to make marriages healthy by Act of Parliament. On March 4th the Senate of that State passed a Bill intended to limit divorces in the State by preventing ill-chosen marriages. The Bill provides for the appointment of a commission by the Governor which shall be composed of two women, who are mothers, two physicians of acknowledged ability, and one attorney of high standing, who shall prepare rules for the guidance of officers in the issue of marriage licences and of ministers in performing ceremonies; and examinations shall be made of all applicants for licences, and no marriages shall be celebrated in the State unless the requirements are complied with. The idea "back of the Bill," we are told, is to require physical examinations and an inquiry into the parentage of the applicants to the end that their union may be prevented in the event that conditions inimical to the welfare of society should be foreshadowed as a result of marriage.

(BMJ 1901;i:1040) 